\title{
The use of a functional approach as surrogate of Collembola species richness in European perennial crops and forests
}

\author{
Filipa Reis ${ }^{\mathrm{a}, *, 1}$, Filipe Carvalho ${ }^{\mathrm{a}, 1}$, Pedro Martins da Silva ${ }^{\mathrm{a}}$, Sara Mendes ${ }^{\mathrm{a}}$, \\ Sónia A.P. Santos ${ }^{\mathrm{b}}$, José Paulo Sousa ${ }^{\mathrm{a}}$ \\ a Centre for Functional Ecology, Department of Life Sciences, University of Coimbra, Calçada Martim de Freitas, 3000-456 Coimbra, Portugal \\ ${ }^{\mathrm{b}}$ Mountain Research Centre (CIMO), School of Agriculture, Polytechnic Institute of Braganç, PO Box 1172, 5301-855 Braganç, Portugal
}

\section{A R T I C L E I N F O}

\section{Article history:}

Received 20 April 2015

Received in revised form

30 September 2015

Accepted 5 October 2015

Available online 7 November 2015

\section{Keywords:}

Community traits

Functional diversity

Indicator tools

Biodiversity monitoring programmes

Soil quality

\begin{abstract}
A B S T R A C T
Collembolans are known indicators of soil disturbance, used in several soil biodiversity monitoring programmes. As for other groups of soil microarthropods, taxonomic determination of Collembola species requires a huge effort and expert knowledge. In this study, we evaluated whether identification of Collembola species to the morphotype level, using an eco-morphological index which classifies individuals based on their adaptation to the soil, can be used as a surrogate of species richness in extensive monitoring schemes. The same evaluation was performed for higher taxa surrogates, using taxonomic categories at the genus and family levels. Additionally, sampling effort for perennial crops and forest systems was determined. Species data were collected from 35 sites sampled within different projects with the same number of samples (16 per site). Results showed that, on average, 8-12 samples are enough to have a good estimate of species richness for this type of systems, averaging $80-90 \%$, but varying considerably with site habitat heterogeneity and local Collembola species pool. GLM models (using species richness as response variable) fitted for family, genus or morphotype levels (explanatory variables) were all significant $(p<0.05)$ but only the latter two had a pseudo $R^{2}$ higher than 0.75 . This indicates that when a rapid, cost-effective assessment of Collembola richness in different sites is required, this eco-morphological trait approach, as well as the determination to the genus level, could be used.
\end{abstract}

(c) 2015 Elsevier Ltd. All rights reserved.

\section{Introduction}

Decline of soil biodiversity has been identified as one of the main threats to soil functioning and sustainability of natural and semi-natural ecosystems (Kibblewhite et al., 2008). Currently, some extensive monitoring schemes have been used in Europe for assessing soil quality and biodiversity, mainly in agro-ecosystems (Breure et al., 2005; Gardi et al., 2009). However, because these monitoring programmes often involve the determination of the soil organisms to the species level, they are too expensive to be used over a broad scale, across ecosystems and eco-regions, and at the desired frequency, necessary to detect deviations from species richness "normal operational range".

To overcome this caveat, several alternative approaches have been suggested to predict species richness and to monitor the spatial and temporal distribution of biodiversity (Cardoso et al., 2004), from which the use of surrogates to invertebrate fauna has been

\footnotetext{
* Corresponding author. Tel.: +351967367738.

E-mail address: ferreirareis.filipa@gmail.com (F. Reis).

1 These authors contributed equally to this work.
}

widely discussed (Andersen, 1995; Biaggini et al., 2007; Brennan et al., 2006; Cardoso et al., 2004; Derraik et al., 2002; Duelli and Obrist, 1998; Lovell et al., 2007; Sauberer et al., 2004).

Surrogacy can use different approaches: the higher taxon approach (Gaston and Williams, 1993) which is addressed in this study, environmental variables (Braithwaite et al., 1989), and species richness of indicator groups (Faith and Walker, 1996).

The higher taxonomic level approach (i.e., using genus or families) is particularly advantageous for large-scale monitoring schemes, since it delivers information on a large number of taxa, while not requiring as many time and resources as a species-level identification would do (Cardoso et al., 2004; Gaston and Williams, 1993), considering that there is a smaller number of higher taxa and they are more easily identified than species.

Despite the advantages of this approach, there are certain factors influencing the relationship between species richness and higher taxa richness that should not be disregarded. Andersen (1995) noted that this relationship is influenced by sampling intensity, since when the number of samples increase, more species belonging to higher level taxa already registered can keep being recorded. Therefore, when doing surrogacy studies, sampling effort is an important factor to take into account. Despite being essential for 
Table 1

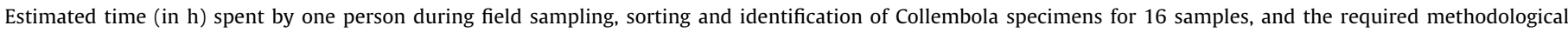

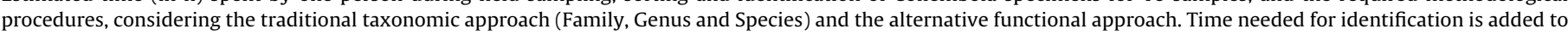
time spent on sorting.

\begin{tabular}{|c|c|c|c|c|c|c|}
\hline & \multirow[t]{2}{*}{ Field work } & \multirow[t]{2}{*}{ Sorting } & \multicolumn{4}{|l|}{ Identification } \\
\hline & & & Morphotypes & Family & Genus & Species \\
\hline Time (h) & 2 & 8 & +4 & +11 & +16 & +28 \\
\hline Methods & $\begin{array}{l}\text { Sampling with } \\
\text { a soil corer }\end{array}$ & \multicolumn{2}{|c|}{ Direct sorting using a stereomicroscope } & $\begin{array}{l}\text { Identification using a stereomicroscope } \\
\text { and, in most cases, mounting } \\
\text { specimens to slides and identification } \\
\text { using ocular/phase microscopy }\end{array}$ & \multicolumn{2}{|c|}{$\begin{array}{l}\text { Further sorting using a stereomicroscope } \\
\text { and mounting specimens to slides and } \\
\text { identification using ocular/phase } \\
\text { microscopy }\end{array}$} \\
\hline
\end{tabular}

species richness estimates in monitoring schemes, sampling effort may fail to depict the actual diversity in a system, particularly for soil communities, since most species are patchily distributed as a result of several spatial and temporal factors (Berg, 2012).

In spite of the large amount of studies carried out on the topic of surrogacy, none was available focusing on soil Collembola and only one was found addressing other groups of soil microarthropods, namely mites (Báldi, 2003). Collembolans are diverse and abundant organisms that act as main drivers in several key soil processes, such as nutrient cycling and organic matter decomposition. Feeding mainly on fungi and bacteria, they act as catalysts of microbial activity affecting decomposition rates (Jeffery et al., 2010). Furthermore, by being affected by agricultural practices and changes in land use (Martins da Silva et al., 2012), they have been widely used as indicators of soil quality and have a high potential of being included in monitoring schemes (Breure et al., 2005; Gardi et al., 2009). For that reason, learning more about the relationship between Collembola species richness and higher taxa richness, and whether this type of surrogacy can be used with some reliability to predict species richness is of great interest. In addition, given the existence of an alternative approach for classifying Collembola species based on their eco-morphological traits (Parisi et al., 2005; Vandewalle et al., 2010), to ascertain if this classification would be a good surrogate to the traditional taxonomic classification would be interesting, since this method could prove much easier to apply due to the reduced time-related costs involved (see Table 1), besides the advantage of being largely independent of biogeographic regions, and then more suitable for monitoring schemes at broader spatial scales (Feld et al., 2009).

Considering this, and from the perspective of the implementation of extensive monitoring schemes, the main goal of this study is to determine, by developing predictive models based on existing data from different projects collected across several European perennial crops and forest stands, if both genera and families higher taxa richness - and a classification based on morphological traits (morphotype richness) can be used as surrogates of Collembola species richness. Furthermore, knowing how important the relationship between surrogacy and sampling effort is when planning extensive monitoring schemes, an evaluation of sampling effort and its connection with richness estimations is intended. We hypothesize that (i) genera is a better surrogate than family and morphotype richness, although morphotypes can ultimately be a very reliable alternative due to its cost-effectiveness, and that (ii) sampling effort is positively related to species richness.

\section{Materials and methods}

\subsection{Study sites}

In order to derive sampling effort and surrogates, abundance data for Collembola species collected in 35 sites from Portugal (60\% of the dataset), Spain, France, Switzerland, Ireland, United Kingdom, Hungary, and Finland with different land cover types was used.
Study sites were selected from different research projects, and thus presenting differences concerning the sampling design, although all sites presented the same sampling effort, i.e., 16 samples per site. The sampling procedure was similar across all sites. Each sample consisted of a soil core with $5 \mathrm{~cm}$ diameter taken from the top $5 \mathrm{~cm}$ soil layer $\left(98 \mathrm{~cm}^{3}\right.$ of soil). When that was not possible (due to the presence of stony soils), a similar soil volume was collected using the same soil depth. Extraction of collembolans was performed either using Berlese funnels (Fafe_PT, Sever_PT, Lousã_PT, Idanha_PT and Almeirim_PT) or a McFadyen High Gradient extractor (the remaining sites). Detailed characterization of the different forest sites can be seen in the following papers: Fafe_PT (Sousa et al., 2003), Sever_PT and Lousã_PT (Da Gama et al., 1995), Idanha_PT (Sousa and da Gama, 1994), Almeirim_PT (Sousa et al., 1997), LU1_PT, LU2_PT, LU1_Finland, LU2_Finland, LU1_France, LU2_France, LU1_Hungary, LU2_Hungary, LU1_Ireland, LU2_Ireland, LU1_Spain, LU2_Spain, LU1_Swiss, LU2_Swiss, LU1_UK, LU2_UK (Sousa et al., 2006). For the perennial crops, nine olive groves were selected (AVB_PT, AVP_PT, CED_PT, GUR_PT, PAR_PT, SPB_PT, SPP_PT, VAL_PT, SUC_PT) all located in the North East region in Portugal (Carvalho, 2012). The selection of the latter sites was based on the different production system adopted in each olive grove: sites under organic production (AVB_PT, SPB_PT, VAL_PT and GUR_PT), where only natural products for both plant control and fertilization are used, and sites under integrated production (AVP_PT, SPP_PT, CED_PT, SUC_PT and PAR_PT), where some synthetic products (pesticides and fertilizers) are allowed. Soil tillage is performed once or twice per year at AVB_PT and AVP_PT sites. Vegetation cut, which consists in cutting herbaceous plants without directly disturbing the soil, is performed at CED_PT, SPB_PT and SUC_PT during summer, and herbicide is always applied under the olive trees at PAR_PT, SUC_PT and SPP_PT sites in spring. Weed control at GUR_PT and VAL_PT is made by sheep grazing at least twice a week.

The 35 sites were separated into five land cover types: broadleaved, coniferous and mixed forests (when broad-leaved and coniferous tree species were present at the same place), Eucalyptus globulus Labill. stands, and Olea europaea L. plantations. Although the latter two could be assigned to the broad-leaved type they were categorized differently as both represented some type of perennial forestry and agriculture systems.

\subsection{Attribution of morphotypes}

For the evaluation of the use of morphotype richness as surrogate for Collembola species richness, a morphotype was attributed to each species present in the data. The morphotype classification was adapted from Vandewalle et al. (2010), which was initially based on the "Qualitá Biologica del Suolo" by Parisi (2001) and Parisi et al. (2005). These classifications attribute a score to each of the following morphological traits: (i) presence/absence of eyes, (ii) length of the antennae, (iii) length of furca, when present, (iv) presence/absence of scales or thick hairs along the body, and (v) pigmentation (Table 2). Higher scores correspond to characteristic morphological features more adapted to deeper soil layers. Each 
Table 2

Morphological traits of Collembola and scores attributed for the establishment of morphotypes.

\begin{tabular}{|c|c|c|}
\hline \multicolumn{2}{|c|}{ Morphological traits } & \multirow{2}{*}{$\begin{array}{l}\text { Score } \\
0\end{array}$} \\
\hline Ocelli & Present & \\
\hline & Absent & 4 \\
\hline \multirow[t]{3}{*}{ Antennae } & Antennae length $>$ body length & 0 \\
\hline & Antennae length $>0.5$ body length & 2 \\
\hline & Antennae length $<0.5$ body length & 4 \\
\hline \multirow[t]{3}{*}{ Furca } & Present (fully developed) & 0 \\
\hline & Present (reduced) & 2 \\
\hline & Absent & 4 \\
\hline \multirow[t]{2}{*}{ Hairs/scales } & Present & 0 \\
\hline & Absent & 4 \\
\hline \multirow[t]{3}{*}{ Pigmentation } & Present with patterns & 0 \\
\hline & Present without patterns & 2 \\
\hline & Absent & 4 \\
\hline
\end{tabular}

specimen is characterized by a combination of five scores, with each different combination being considered a morphotype.

\subsection{Processing species data}

For the derivation of sampling effort and surrogates, some rules had to be taken into account to avoid specimens with unclear identification status to be included in the analysis. For this reason, unidentified juveniles were excluded from the analysis. Other individuals, spread over 16 genera and not identified to species level, were also excluded if following two conditions: (i) if a morphotype could not be attributed and (ii) if there were already species from the same genus present in the same site. In addition, all Mesaphorura species within each site were grouped into a single species, hence Mesaphorura sp. The same procedure was adopted to all Protaphorura species, becoming Protaphorura sp. The reasoning behind this decision was related to the fact that the detail of identification per site in these groups was quite variable.

\subsection{Estimating sampling effort}

Sampling effort (i.e., the number of samples needed to collect a given \% of a site's richness) was calculated using species richness at each site. For the derivation of sampling effort, expected richness values per number of samples and rarefaction curves with the exact method (Kindt et al., 2006; Ugland et al., 2003) were calculated for each site, using the function "speccaccum" in the "vegan" package (Oksanen et al., 2013) in R software (R Core Team, 2013).

Subsequently, these values of the expected richness per accumulated number of samples were fitted to the negative exponential model $-S(t)=a / b \times[1-\operatorname{EXP}(-b \times t)]-$ where $S(t)$ is the number of species at $t$ accumulated samples, $a$ and $b$ parameters regulating the shape of the curve and $a / b$ the asymptote (or maximum predicted number of species) of a given site (Shiu and Lee, 2003). This model was preferred among others because of its low number of parameters and capacity of reaching an asymptote. The measurements were performed using $\mathrm{R}$ formula "nls", and $R^{2}$ values were calculated.

To calculate sampling effort (the number of samples required to achieve a given percentage of total richness), a variation of the same function was also applied: $t_{q}=-1 / b \ln (1-q)$ (Shiu and Lee, 2003), where $q$ is a value between 0 and 1 and $t_{q}$ the number of samples required to sample a $q$ fraction of the total richness.

Sampling effort values were calculated for $60,70,80$ and $90 \%$ of each site asymptote. Total mean and means for each land cover type were calculated. Boxplot graphs of sampling effort were drawn using R package "ggplot2" (Wickham, 2009).
In order to understand the role of the spatial distribution of species to the sampling effort, dissimilarity matrices using the binary version of Jaccard index were performed with package "vegan" in $\mathrm{R}$, and the mean value for each dissimilarity matrix was used as the site mean Jaccard index, which we consider to be an indicator of sample heterogeneity. Where null-null sample comparisons were present those comparisons were not taken into account into the site mean Jaccard dissimilarity index. The Jaccard dissimilarity indices were visually displayed in a bubble graph to show relationships between site richness, site sample heterogeneity and estimated sampling effort at $90 \%$ level of the asymptote.

\subsection{Surrogate models derivation and validation}

Aiming to find out if genera, morphotypes and families can be used as surrogates for species, matrices with the number of species, genera, families and morphotypes per site were built.

Function "glm" in $\mathrm{R}$ was used to develop generalized linear models to predict species richness based on genera, families or morphotypes, using the number of species as dependent variable and the number of genera, families, or morphotypes as independent variables. Poisson distribution with Log link function was used for all models. These models were developed using data from 30 out of the available 35 sites. Model validation was performed using the other 5 sites that were randomly selected beforehand, each belonging to a different land cover type.

\section{Results}

\subsection{Collembola data used}

In total, 51,364 Collembolans, distributed among 219 species, were used in the dataset. Among the sites used for the models development, there were 42,721 individuals distributed in $23 \mathrm{fam}$ ilies, 84 genera, 213 species and 23 morphotypes. In the validation dataset, 8673 individuals were distributed in 19 families, 60 genera, 97 species and 21 morphotypes.

\subsection{Sampling effort}

The applied negative exponential model allowed the estimation of the number of samples required to estimate $60,70,80$, and $90 \%$ of the sites' richness $-5,6,8$, and 12 samples, respectively (Table 3 ).

For most sites the asymptote was reached, in several cases corresponding to lower values than those of the total richness observed (i.e., Fafe_Q_PT, Fafe_E_PT, Sever_E_PT, Table 3), indicating that the number of samples collected in those site was enough to estimate the complete species richness of that particular forest stand and, theoretically, no more species are to be recorded.

The average sampling effort per land cover type varied significantly, E. globulus and $O$. europaea being the ones requiring more samples to obtain a given fraction of species richness (Fig. 1).

The correlation between sampling effort and mean sample dissimilarity (Fig. 2) indicates that sampling effort seems to be correlated not with local species richness, but with sample heterogeneity. Sites with a higher number of null samples require a higher sampling effort.

\subsection{Surrogates of Collembola species richness}

\subsubsection{Predictive models}

The developed generalized linear models resulted in the three following equations for prediction of species richness (S_Coll_sp) based on morphotype richness (S_Coll_morph), number of genera (S_Coll_gen), and number of families (S_Coll_fam), respectively: 
Table 3

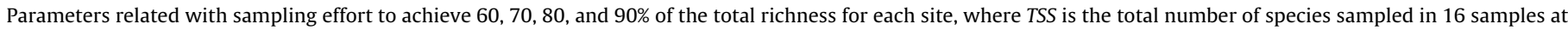
each site.

\begin{tabular}{|c|c|c|c|c|c|c|c|c|c|}
\hline Site & Type & TSS & Asymptote & \%Asymptote & $R^{2}$ & $t(60 \%)$ & $t(70 \%)$ & $t(80 \%)$ & $t(90 \%)$ \\
\hline Fafe_Q_PT & Broad-leaf & 30 & 29.1 & 103.1 & 0.96 & 3.2 & 4.2 & 5.6 & 8 \\
\hline Fafe_E_PT & Eucalyptus & 26 & 25.4 & 102.4 & 0.98 & 3.6 & 4.8 & 6.4 & 9.2 \\
\hline Sever_P_PT & Coniferous & 36 & 35.9 & 100.3 & 0.99 & 4.2 & 5.5 & 7.4 & 10.5 \\
\hline Sever_E_PT & Eucalyptus & 31 & 29.1 & 106.5 & 0.92 & 2.6 & 3.4 & 4.5 & 6.4 \\
\hline Lousa_P_PT & Coniferous & 33 & 31.3 & 105.4 & 0.93 & 2.2 & 2.9 & 3.8 & 5.5 \\
\hline Lousa_E_PT & Eucalyptus & 38 & 36.9 & 103.0 & 0.96 & 3.3 & 4.3 & 5.8 & 8.3 \\
\hline Idanha_Q_PT & Broad-leaf & 38 & 37.2 & 102.2 & 0.98 & 3 & 4 & 5.3 & 7.6 \\
\hline Idanha_E_PT & Eucalyptus & 19 & 21.3 & 89.2 & 0.99 & 7.3 & 9.6 & 12.9 & 18.4 \\
\hline Almeirim_Q_PT & Broad-leaf & 15 & 14.7 & 102.0 & 0.97 & 3.3 & 4.3 & 5.8 & 8.2 \\
\hline Almeirim_E_PT & Eucalyptus & 19 & 21.5 & 88.4 & 0.99 & 7.4 & 9.7 & 13 & 18.5 \\
\hline AVB_PT & Olea & 5 & 5 & 100.0 & 0.99 & 4.9 & 6.5 & 8.7 & 12.4 \\
\hline AVP_PT & Olea & 11 & 11.6 & 94.8 & 0.99 & 6 & 7.9 & 10.6 & 15.2 \\
\hline CED_PT & Olea & 12 & 11.8 & 101.7 & 0.98 & 4.2 & 5.5 & 7.4 & 10.6 \\
\hline GUR_PT & Olea & 15 & 17 & 88.2 & 0.99 & 7.5 & 9.9 & 13.2 & 18.9 \\
\hline PAR_PT & Olea & 12 & 11.3 & 106.2 & 0.93 & 3 & 4 & 5.3 & 7.6 \\
\hline SPB_PT & Olea & 13 & 12.5 & 104.0 & 0.94 & 3.6 & 4.7 & 6.3 & 9.1 \\
\hline SPP_PT & Olea & 12 & 12.6 & 95.2 & 0.98 & 6 & 7.9 & 10.6 & 15.1 \\
\hline SUC_PT & Olea & 11 & 12 & 91.7 & 0.99 & 6.6 & 8.7 & 11.6 & 16.6 \\
\hline VAL_PT & Olea & 17 & 20.3 & 83.7 & 1.00 & 8.4 & 11.1 & 14.8 & 21.2 \\
\hline LU1_PT & Broad-leaf & 34 & 33.5 & 101.5 & 0.99 & 3.9 & 5.2 & 6.9 & 9.9 \\
\hline LU2_PT & Eucalyptus & 10 & 10.7 & 93.5 & 0.99 & 6.2 & 8.2 & 10.9 & 15.6 \\
\hline LU1_Finland & Coniferous & 26 & 24.6 & 105.7 & 0.95 & 2.6 & 3.4 & 4.6 & 6.6 \\
\hline LU2_Finland & Coniferous & 24 & 22.8 & 105.3 & 0.96 & 2.9 & 3.8 & 5 & 7.2 \\
\hline LU1_France & Broad-leaf & 37 & 35.2 & 105.1 & 0.94 & 3.2 & 4.3 & 5.7 & 8.1 \\
\hline LU2_France & Coniferous & 37 & 35.7 & 103.6 & 0.96 & 3.5 & 4.6 & 6.1 & 8.8 \\
\hline LU1_Hungary & Broad-leaf & 20 & 22.4 & 89.3 & 1.00 & 7 & 9.1 & 12.2 & 17.5 \\
\hline LU2_Hungary & Mixed & 28 & 28.8 & 97.2 & 1.00 & 4.7 & 6.2 & 8.3 & 11.9 \\
\hline LU1_Ireland & Mixed & 24 & 24.8 & 96.8 & 0.98 & 5.4 & 7.1 & 9.5 & 13.6 \\
\hline LU2_Ireland & Coniferous & 23 & 24.9 & 92.4 & 0.98 & 6.8 & 8.9 & 11.9 & 17 \\
\hline LU1_Spain & Broad-leaf & 46 & 44.7 & 102.9 & 0.97 & 3.9 & 5.2 & 6.9 & 9.9 \\
\hline LU2_Spain & Coniferous & 30 & 30 & 100.0 & 0.98 & 4.7 & 6.1 & 8.2 & 11.7 \\
\hline LU1_Swiss & Mixed & 42 & 41.7 & 100.7 & 0.98 & 4.2 & 5.6 & 7.4 & 10.6 \\
\hline LU2_Swiss & Mixed & 42 & 40.6 & 103.4 & 0.97 & 2.9 & 3.8 & 5 & 7.2 \\
\hline LU1_UK & Coniferous & 6 & 6.2 & 96.8 & 0.98 & 5.5 & 7.3 & 9.7 & 13.9 \\
\hline \multirow[t]{2}{*}{ LU2_UK } & Coniferous & 8 & 8 & 100.0 & 0.98 & 4.7 & 6.2 & 8.3 & 11.8 \\
\hline & & & & & $\operatorname{Mean}(t)$ & 4.6 & 6.1 & 8.2 & 11.7 \\
\hline
\end{tabular}

S_Coll_sp $=\exp (1.452+0.147 \times$ S_Coll_morph $)$

Pseudo $R^{2}=75 \%$

S_Coll_sp $=\exp (1.837+0.06 \times$ S_Coll_gen $)$

Pseudo $R^{2}=95 \%$

S_Coll_sp $=\exp \left(1.898+0.116 \times S_{\text {_CCOll_fam }}\right)$

Pseudo $R^{2}=68 \%$

For all the equations, independent variables were highly significant $(p<0.001)$ having originated high pseudo $R^{2}$ values.

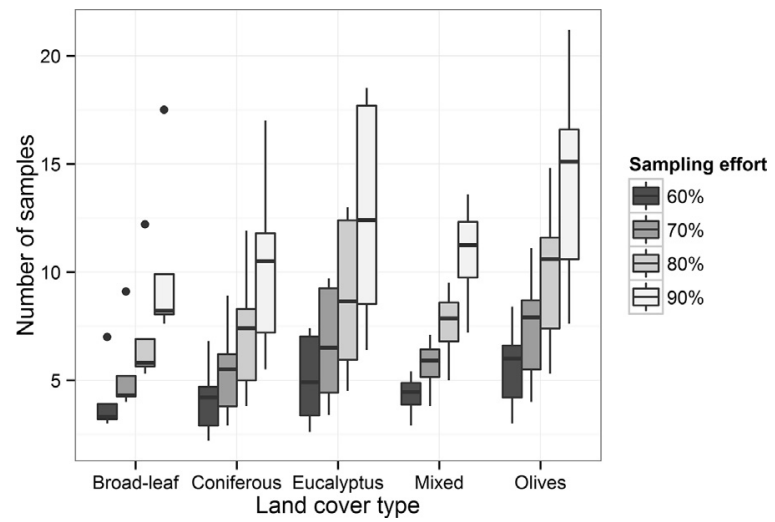

Fig. 1. Boxplots of the median number of samples required to estimate $60,70,80$ and $90 \%$ of the total richness, per forest type.

\subsubsection{Model validation}

Each fitted equation is represented in Fig. 3. The five sites used for validation behave well against all fitted curves, being always well inside the $95 \%$ confidence limits, confirming the validity of the developed models.

\section{Discussion}

\subsection{Sampling effort}

Some of the studied sites clearly needed a larger number of samples (over 12) to attain $80-90 \%$ of total species richness. This was

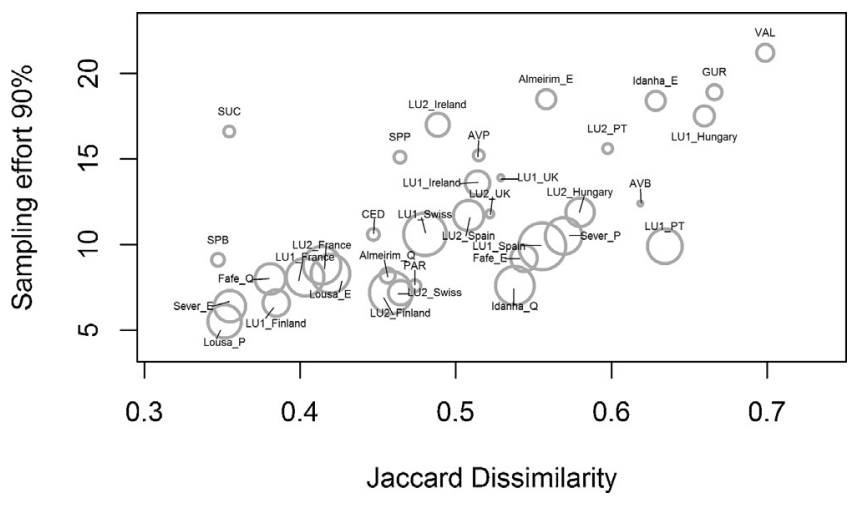

Fig. 2. Relation between sampling effort to estimate $90 \%$ of species richness and mean sample richness dissimilarity per site. Larger circles indicate higher richness in that specific site. 

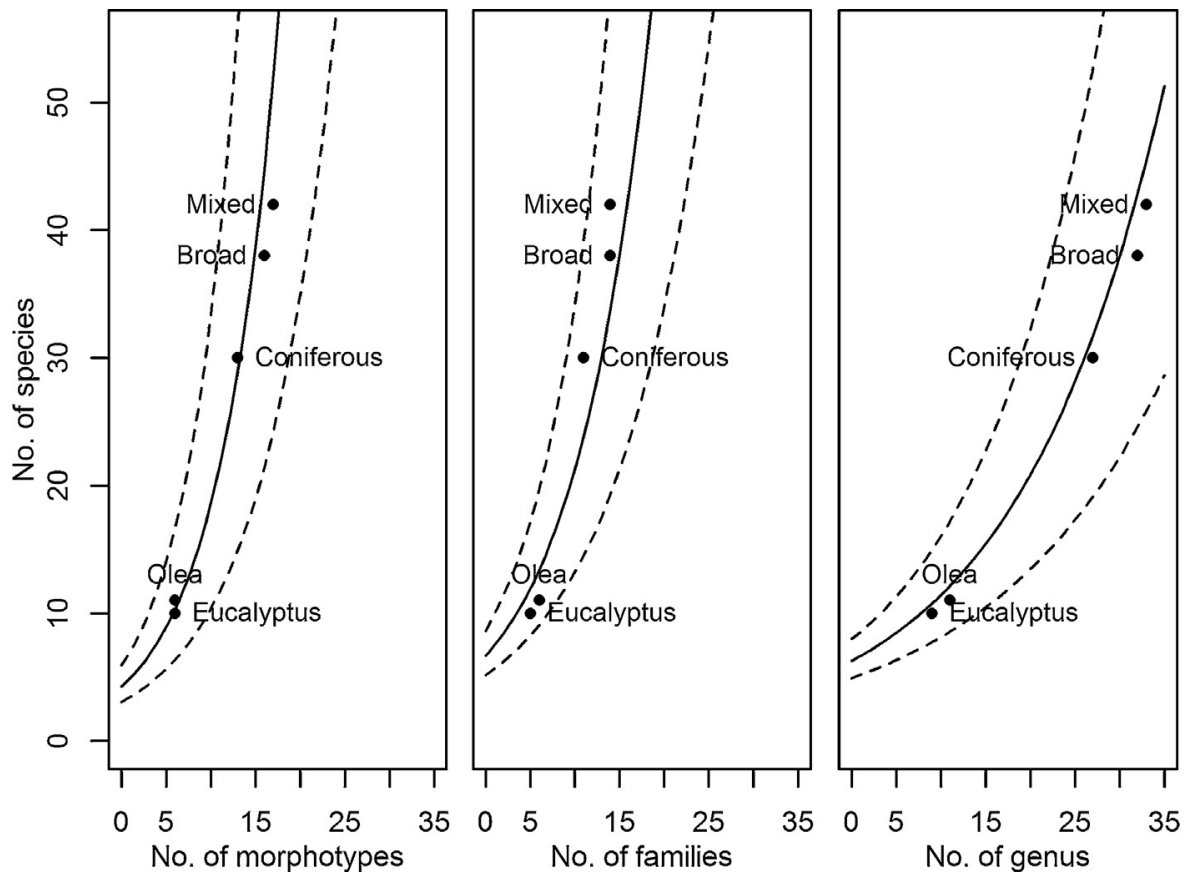

Fig. 3. Fitted curves and $95 \%$ confidence intervals versus the validation sites, for the morphotypes, families and genera models of species surrogacy.

noticeable in some E. globulus and O. europaea stands. Although this may seem strange, particularly in the eucalyptus sites, known by having a general lower species richness than other forest stands from the same region (Sousa et al., 2000), this finding is most probably associated with the heterogeneous structure of the habitat, since more heterogeneous sites will naturally require a larger number of samples to attain the same relative level of species richness (Boulinier et al., 1998; Gotelli and Colwell, 2001). Several of the sampled eucalyptus sites presented a spatially heterogeneous habitat configuration, with tree rows having medium to high accumulation of plant residues, whereas between row spaces being depleted of soil cover (Sousa et al., 2000). Furthermore, E. globulus and $O$. europaea sites were more intensively managed than the other sites studied, which is in agreement with Flather (1996), who found that more pressured landscapes required a larger amount of samples in order to reach an asymptote, by stating that less species would mean that a bigger proportion of the community would be found more rarely.

The positive correlation between the Jaccard dissimilarity index and the sampling effort indicated that the dissimilarity between samples and thus, species patchiness, was the major driver influencing the number of samples required. This contradicted our second working hypothesis. However, since the distribution patterns of soil biodiversity are associated with habitat heterogeneity (at a local scale) and with disturbance and vegetation patchiness (at landscape scale) (Bardgett, 2005), these results can be considered further evidence of the heterogeneity aspect discussed above. The next step could be then the use of "mocking" communities, i.e., communities with known spatial distributions, and perform simulations on them with different types of distribution to further understand the impact of habitat heterogeneity on sampling effort.

The obtained results imply that it is important to take into account the degree of heterogeneity and human intervention when defining the sampling effort in a monitoring scheme.

\subsection{Surrogates of richness}

Lovell et al. (2007) defined a minimum threshold in $R^{2}$ values of 0.75 in order to select good surrogates. Following the same approach for pseudo $R^{2}$ values, the number of genera seemed to be a very reliable substitute of species richness, thus confirming our first working hypothesis. This was expected given the high correlation found between species richness and higher taxa richness in past surrogacy studies related with soil arthropods (Báldi, 2003; Biaggini et al., 2007; Cardoso et al., 2004; Forest Focus, 2007). Nevertheless it must be noted that, in this study, richness in some speciose genera like Mesaphorura and Protaphorura has been underestimated. The pseudo $R^{2}$ value for the morphotypes was just about the threshold, thus they can be used with some degree of confidence to replace species richness, unlike the family level which performed below the threshold. Therefore, when compared with the number of families, morphotypes achieved higher precision with less effort.

Some attempts in using Collembola eco-morphological traits as indicators of soil quality have been performed in the past, for instance the QBS index (Parisi, 2001; Parisi et al., 2005), which evaluates the adaptability of the Collembola fauna to the soil profile and assumes that the soil has a higher quality when more adapted forms are present. Three main aspects of a functional approach are very suitable for monitoring schemes: (i) practicability - often these approaches do not require specialized knowledge on taxonomic groups and hence can be more broadly used by para-taxonomists (Oliver and Beattie, 1996); (ii) functionality - usually they provide the researchers more mechanistic and functional point of view of a community (Feld et al., 2009; Vandewalle et al., 2010); and (iii) comparability - they usually allow the comparison between different ecosystems within different eco-regions, because although species richness and composition will be different, their species functional traits will always be comparable (Feld et al., 2009; Pey et al., 2014). The method analyzed in this study accomplishes these three hallmarks: (i) individuals are significantly easier to assign to the morphotype than to the family or genus level, (ii) they provide the user quantified data on how the community is adapted to the soil profile, hence delivering additional information related with the communities' response to stress factors, which are not necessarily detected in species diversity (Vandewalle et al., 2010) and thus (iii) facilitating the comparison between ecosystems from different eco-regions and different European forest stands. 
However, this approach only accounts for the "Collembola component" of soil invertebrate richness. An interesting approach on the subject would be to test the effectiveness of Collembola as a surrogate group of other soil taxa. In this respect, not only species richness but also other types of surrogacy, such as community composition similarity, should be tested (Su et al., 2004), since cross-taxon relationships can vary greatly according to spatial scales and geographic location (Prendergast and Eversham, 1997). On a final note, it is important to mention that the use of surrogates should not be generally adopted as a substitute to species determination. Surrogates may be useful in extensive monitoring schemes, where time and cost might be limiting, but they can never yield information as accurate as species determination would (Moreno et al., 2008).

\section{Conclusions}

The derivation of sampling effort for soil mesofauna offers practical information for the planning of monitoring schemes, allowing the adoption of a less expensive and time-consuming sampling method without severely compromising the richness estimated in a site. Both the number of morphotypes and the number of genera proved to be good surrogates of species richness. However, when considering rapid biodiversity assessments, we believe that the use of morphotypes could be adopted since it requires less time, expertise and materials. If combined with efficient sampling effort, this approach is a very useful tool due to its simplicity and the possibility of incorporating the functional component of diversity in these monitoring plans and across region comparisons. Thus, the results obtained in this paper can potentially contribute to the goal of monitoring soil biodiversity in European perennial crops and forests, by presenting cost-efficient solutions towards an extensive monitoring of soil biodiversity.

\section{Acknowledgements}

We would like to thank Paulo A.V. Borges and an anonymous reviewer for the helpful comments and suggestions to the early versions of the manuscript.

This work was funded by Fundação para a Ciência e Tecnologia through the project PTDC/AGR-PRO/111123/2009: the use of biological indicators as tools for assessing the impact of agricultural practices in sustainability of olive grove.

\section{References}

Andersen, A.N., 1995. Measuring more of biodiversity: genus richness as a surrogate for species richness in Australian ant faunas. Biol. Conserv. 73, 39-43, http://dx. doi.org/10.1016/0006-3207(95)90059-4.

Báldi, A., 2003. Using higher taxa as surrogates of species richness: a study based on 3700 Coleoptera Diptera, and Acari species in Central-Hungarian reserves. Basic Appl. Ecol. 4, 589-593, http://dx.doi.org/10.1078/1439-1791-00193.

Bardgett, R.D., 2005. The diversity of life in soil. In: Crawley, M.J., Little, C., Southwood, T.R.E., Ulfstrand, S. (Eds.), The Biology of Soil - A Community and Ecosystem Approach. Oxford University Press, Oxford, pp. 24-56.

Berg, M.P., 2012. Patterns of biodiversity at fine and small spatial scales. In: Wall, D.H. (Ed.), Soil Ecology and Ecosystem Services. Oxford University Press, Oxford, pp. 136-152.

Biaggini, M., Consorti, R., Dapporto, L., Dellacasa, M., Paggetti, E., Corti, C., 2007. The taxonomic level order as a possible tool for rapid assessment of Arthropod diversity in agricultural landscapes. Agric. Ecosyst. Environ. 122, 183-191, http://dx. doi.org/10.1016/j.agee.2006.12.032.

Boulinier, T., Nichols, J.D., Sauer, J.R., Hines, J.E., Pollock, K.H., 1998. Estimating species richness: the importance of heterogeneity in species detectability. Ecology 79, 1018-1028, http://dx.doi.org/10.1890/00129658(1998)079[1018:ESRTIO]2.0.CO;2.

Braithwaite, L.W., Austin, M.P., Clayton, M., Turner, J., Nicholls, A.O., 1989. On predicting the presence of birds in Eucalyptus forest types. Biol. Conserv. 50, 33-50, http://dx.doi.org/10.1016/0006-3207(89)90004-9.

Brennan, K.E.C., Ashby, L., Majer, J.D., Moir, M.L., Koch, J.M., 2006. Simplifying assessment of forest management practices for invertebrates: how effective are higher taxon and habitat surrogates for spiders following prescribed burning? Forest Ecol. Manage. 231, 138-154, http://dx.doi.org/10.1016/j.foreco.2006.05.035.

Breure, A.M., Mulder, C., Römbke, J., Ruf, A., 2005. Ecological classification and assessment concepts in soil protection. Ecotoxicol. Environ. Saf. 62, 211-229, http:// dx.doi.org/10.1016/j.ecoenv.2005.03.025.

Cardoso, P., Silva, I., de Oliveira, N.G., Serrano, A.R., 2004. Higher taxa surrogates of spider (Araneae) diversity and their efficiency in conservation. Biol. Conserv. 117, 453-459, http://dx.doi.org/10.1016/j.biocon.2003.08.013.

Carvalho, F.C., (MSc thesis) 2012. Efeito de diferentes tipos de gestão em olivais nos microartrópodes de solo usando uma abordagem functional. University of Coimbra http://hdl.handle.net/10316/24991.

Da Gama, M.M., Sousa, J.P., Vasconcelos, T.M., 1995. Comparison of Collembolan population structure from Portuguese forests of Pinus pinaster Aiton and Eucalyptus globulus Labill. Bull. Entomol. Pol. 64, 77-89.

Derraik, J.G., Closs, G.P., Dickinson, K.J., Sirvid, P., Barratt, B.I., Patrick, B.H., 2002 Arthropod morphospecies versus taxonomic species: a case study with Araneae Coleoptera, and Lepidoptera. Conserv. Biol. 16, 1015-1023, http://dx.doi.org/10. 1046/j.1523-1739.2002.00358.x.

Duelli, P., Obrist, M.K., 1998. In search of the best correlates for local organismal biodiversity in cultivated areas. Biodivers. Conserv. 7, 297-309, http://dx.doi. org/10.1023/A:1008873510817.

Faith, D., Walker, P., 1996. How do indicator groups provide information about the relative biodiversity of different sets of areas? On hotspots, complementarity and pattern-based approaches. Biodiver. Lett. 3, 18-25, http://dx.doi.org/ $10.2307 / 2999706$.

Feld, C.K., Martins da Silva, P., Sousa, J.P., de Bello, F., Bugter, R., Grandin, U., Hering, D., Lavorel, S., Mountford, O., Pardo, I., Pärtel, M., Römbke, J., Sandin, L., Jones, K.B., Harrison, P., 2009. Indicators of biodiversity and ecosystem services: a synthesis across ecosystems and spatial scales. Oikos 118, 1862-1871, http://dx.doi.org/ 10.1111/j.1600-0706.2009.17860.x.

Flather, C.H., 1996. Fitting species-accumulation functions and assessing regional land use impacts on avian diversity. J. Biogeogr. 23, 155-168, http://dx.doi.org/ 10.1046/j.1365-2699.1996.00980.x.

Gardi, C., Montanarella, L., Arrouays, D., Bispo, A., Lemanceau, P., Jolivet, C., Mulder, C., Ranjard, L., Römbke, J., Rutgers, M., Menta, C., 2009. Soil biodiversity monitoring in Europe: ongoing activities and challenges. Eur. J. Soil Sci. 60, 807-819, http:/| dx.doi.org/10.1111/j.1365-2389.2009.01177.x.

Gaston, K.J., Williams, P.H., 1993. Mapping the world's species - the higher taxon approach. Biodiver. Lett. 1, 2-8, http://dx.doi.org/10.2307/2999642.

Gotelli, N.J., Colwell, R.K., 2001. Quantifying biodiversity: procedures and pitfalls in the measurement and comparison of species richness. Ecol. Lett. 4, 379-391, http://dx.doi.org/10.1046/j.1461-0248.2001.00230.x.

Jeffery, S., Gardi, C., Jones, A., Montanarella, L., Marmo, L., Miko, L., Ritz, K., Peres, G., Römbke, J., van der Putten, W.H. (Eds.), 2010. European Atlas of Soil Biodiversity. European Commission, Publications Office of the European Union, Luxembourg.

Kibblewhite, M.G., Jones, R.J.A., Baritz, R., Huber, S., Arrouays, D., Micheli, E. Stephens, M., 2008. ENVASSO Final Report Part I: Scientific and Technical Activities. ENVASSO Project (Contract 022713) coordinated by Cranfield University, UK, for Scientific Support to Policy, European Commission 6th Framework Research Programme.

Kindt, R., Van Damme, P., Simons, A.J., 2006. Patterns of species richness at varying scales in western Kenya: planning for agroecosystem diversification. Biodiver. Conserv. 15, 3235-3249, http://dx.doi.org/10.1007/s10531-005-0311-9.

Lovell, S., Hamer, M., Slotow, R., Herbert, D., 2007. Assessment of congruency across invertebrate taxa and taxonomic levels to identify potential surrogates. Biol. Conserv. 139, 113-125, http://dx.doi.org/10.1016/j.biocon.2007.06.008.

Martins da Silva, P., Berg, M.P., Serrano, A.R.M., Dubs, F., Sousa, J.P., 2012. Environmental factors at different spatial scales governing soil fauna community patterns in fragmented forests. Landsc. Ecol. 27, 1337-1349, http://dx.doi.org/ 10.1007/s10980-012-9788-2.

Moreno, C.E., Guevara, R., Sánchez-Rojas, G., Téllez, D., Verdú, J.R., 2008. Community level patterns in diverse systems: a case study of litter fauna in a Mexican pineoak forest using higher taxa surrogates and re-sampling methods. Acta Oecol. 33, 73-84, http://dx.doi.org/10.1016/j.actao.2007.09.002.

Oksanen, J., Blanchet, F.G., Kindt, R., Legendre, P., Minchin, P.R., O’Hara, R.B., Simpson, G.L., Solymos, P., Henry, M., Stevens, H., Wagner, H., 2013. vegan: Community Ecology Package. R Package Version 2.0-10. http://CRAN.R-project.org/ package=vegan.

Oliver, I., Beattie, A.J., 1996. Invertebrate morphospecies as surrogates for species: a case study. Conserv. Biol. 10, 99-109, http://dx.doi.org/10.1046/j.1523-1739. 1996.10010099.x.

Parisi, V., 2001. La qualità biologica del suolo. Un metodo basato sui microartropodi. Acta Naturalia de L'Ateno Parmense 37, 97-106.

Parisi, V., Menta, C., Gardi, C., Jacomini, C., Mozzanica, E., 2005. Microarthropod communities as a tool to assess soil quality and biodiversity: a new approach in Italy. Agric. Ecosyst. Environ. 105, 323-333, http://dx.doi.org/10.1016/j.agee.2004.02 002 .

Pey, B., Nahmani, J., Auclerc, A., Capowiez, Y., Cluzeau, D., Cortet, J., Decaëns, T., Deharveng, L., Dubs, F., Joimel, S., Briard, C., Grumiaux, F., Laporte, M.A., Pasquet, A., Pelosi, C., Pernin, C., Ponge, J.F., Salmon, S., Santorufo, L., Hedde, M., 2014. Current use of and future needs for soil invertebrate functional traits in community ecology. Basic Appl. Ecol. 15, 194-206, http://dx.doi.org/10.1016/j.baae. 2014.03.007.

Prendergast, J.R., Eversham, B.C., 1997. Species richness covariance in higher taxa: empirical tests of the biodiversity indicator concept. Ecography 20, 210-216, http://dx.doi.org/10.1111/j.1600-0587.1997.tb00363.x. 
Programa Nacional "Forest Focus" (Actividade C2), 2007. Implementing an operational methodology for biodiversity monitoring in Portuguese forests. Relatório de Execução Técnica.

R Core Team, 2013. R: A Language and Environment for Statistical Computing. R Foundation for Statistical Computing, Vienna, Austria http://www.R-project. org/.

Sauberer, N., Zulka, K.P., Abensperg-Traun, M., Berg, H.-M., Bieringer, G., Milasowszky, N., Moser, D., Plutzar, C., Pollheimer, M., Storch, C., Tröstl, R., Zechmeister, H., Grabherr, G., 2004. Surrogate taxa for biodiversity in agricultural landscapes of eastern Austria. Biol. Conserv. 117, 181-190, http://dx.doi. org/10.1016/S0006-3207(03)00291-X.

Shiu, H.-J., Lee, P.-F., 2003. Assessing avian point-count duration and sample size using species accumulation functions. Zool. Stud. 42, 357-367.

Sousa, J.P., da Gama, M.M., 1994. Rupture in a Collembola community structure from a Quercus rotundifolia Lam. forest due to reafforestation with Eucalyptus globulus Labill. Eur. J. Soil Biol. 30, 71-78.

Sousa, J.P., Vingada, J.V., Barrocas, H., da Gama, M.M., 1997. Effects of introduced exotic tree species on Collembola communities: the importance of management techniques. Pedobiologia 41, 145-153.

Sousa, J.P., da Gama, M.M., Ferreira, C., Barrocas, H., 2000. Effect of eucalyptus plantations on Collembola communities in Portugal: a review. Belg. J. Entomol. 2, 187-201.
Sousa, J.P., da Gama, M.M., Ferreira, C.S., 2003. Effects of replacing oak-woods by eucalyptus on edaphic Collembola communities: does the size and type of plantation matter? Acta Entomológica Ibérica e Macaronésica 1, 1-10.

Sousa, J.P., Bolger, T. da Gama, M.M., Lukkari, T., Ponge, J.-F., Simón, C., Traser, G. Vanbergen, A., Brennan, A., Dubs, F., Ivitis, E., Keating, A., Stofer, A., Watt, A.D. 2006. Changes in Collembola richness and diversity along a gradient of land-use intensity: a pan European study. Pedobiologia 50, 147-156, http://dx.doi.org 10.1016/j.pedobi.2005.10.005.

Su, J.C., Debinski, D.M., Jakubauskas, M.E., Kindscher, K., 2004. Beyond species richness: community similarity as a measure of cross-taxon congruence for coarse-filter conservation. Conserv. Biol. 18, 167-173, http://dx.doi.org/10. 1111/j.1523-1739.2004.00337.x.

Ugland, K.I., Gray, J.S., Ellingsen, K.E., 2003. The species - accumulation curve and estimation of species richness. J. Anim. Ecol. 72, 888-897, http://dx.doi.org/10. 1046/j.1365-2656.2003.00748.x.

Vandewalle, M., Bello, F., Berg, M.P., Bolger, T., Dolédec, S., Dubs, F., Feld, C.K., Harring ton, R., Harrison, P.A., Lavorel, S., Silva, P.M., Moretti, M., Niemelä, J., Santos, P., Sattler, T., Sousa, J.P., Sykes, M.T., Vanbergen, A.J., Woodcock, B.A., 2010. Functional traits as indicators of biodiversity response to land use changes across ecosystems and organisms. Biodiver. Conserv. 19, 2921-2947, http://dx.doi.org/ 10.1007/s10531-010-9798-9.

Wickham, H., 2009. ggplot2: Elegant Graphics for Data Analysis. Springer, New York. 